\title{
O papel do programa Minha casa, minha vida no processo de construção das cidades: a perspectiva configuracional
}

\author{
The role of "Minha casa, minha vida" program in the cities \\ building process: the configurational perspective
}

Alice de Almeida Vasconcellos de Carvalho, Valério Augusto Soares de Medeiros

Universidade de Brasília (UnB), Brasília, DF, Brasil

\section{Resumo}

\begin{abstract}
A literatura aponta a fragmentação espacial caracterizada pela "colcha de retalhos" como uma das feições mais marcantes das cidades brasileiras. Considerando que a política habitacional recente, ao disponibilizar vultosos recursos para a construção de moradias por meio do Programa Minha Casa Minha Vida (PMCMV), vem impactando substancialmente as estruturas urbanas, seja pela expansão ou consolidação do tecido, explora-se neste artigo a relação entre o programa e a produção do espaço urbano, na perspectiva configuracional. Utilizando-se do aparato teórico, metodológico e ferramental advindo da Sintaxe Espacial ou Teoria da Lógica Social do Espaço, analisam-se os empreendimentos contratados pelo PMCMV por meio do Fundo de Arrendamento Residencial - FAR em 24 capitais estaduais brasileiras, de modo a compreender, a partir da análise comparativa em caráter exploratório, em que medida esses empreendimentos impactam o tecido urbano, em termos relacionais. A hipótese a ser testada é de que as novas áreas impulsionadas pelo PMCMV seguem a mesma tendência de fragmentação do tecido identificada em cidades brasileiras, reforçando a segregação sócio espacial existente. No entanto, os achados apontaram um cenário heterogêneo, verificando que não se deve reputar ao programa, de forma generalizada, a piora no quadro de fragmentação/dispersão do tecido, que vem sendo uma característica das cidades do país há décadas.
\end{abstract}

Palavras-chave: Configuração urbana. Sintaxe Espacial. Política habitacional. Cidades brasileiras.

Programa "Minha Casa, Minha Vida".

AAVC é arquiteta e analista de infraestrutura, Desenvolvimento e Gestão, Mestre, e-mail: avcarvalho.alice@gmail.com VASM é arquiteto e analista legislativo, Doutor, e-mail: vaugusto@unb.br 


\section{Abstract}

The analysis of the literature review defines the spatial fragmentation based on a patchwork pattern as one of the main features of the Brazilian urban fabric. Considering that the recent housing policy, by providing a significance resources to build houses in "Minha Casa, Minha Vida" Program (PMCMV), impacts substantially the Brazilian cities, by either expanding or consolidating the urban grid, this paper explores the relationship between the national housing policies associated with the PMCMV and the urban configuration. The research focus is morphological, according to the theoretical, methodological and technical approach offered by the Theory of the Social Logic of Space (Space Syntax), considering a comparative and exploratory perspective. The analysis are focused in the developments contracted in the "Fundo de Arrendamento Residencial - FAR" category, in 24 Brazilian capitals, aiming at discussing to what extent these real estate developments caused impact in the urban network, taking into account a relational perspective. The evaluated hypothesis is that the new areas developed by means of the PMCMV follow the same fragmentary tendency identified in the country's major cities, stressing the socio-spatial segregation. Findings, however, have suggested a more heterogeneous situation, in both negative and positive ways: sometimes the developments help to better connect the urban grid.

Keywords: Urban configuration. Urban syntax. Housing policies. Brazilian cities. "Minha Casa, Minha Vida" Program.

\section{Introdução}

A pesquisa baseia-se no estudo da configuração urbana, na medida em que reconhece haver uma relação entre o espaço - enquanto produto da forma - e a estrutura social - enquanto modo de interação entre os indivíduos. A leitura da cidade explora o conceito de "lógica social" derivado da Sintaxe Espacial, que se refere "à maneira como a forma é constituinte de relações de simetria ou assimetria entre classes ou grupos sociais de natureza variada, isto é, como ela é constituinte de relações de poder" (Holanda, 2002, p. 31).

Analisando o vínculo entre as políticas habitacionais e o espaço urbano, consoante a leitura configuracional, avalia-se a fragmentação do tecido como uma das características recorrentes das estruturas urbanas no país. Para Medeiros (2013), as cidades no Brasil são marcadas por características peculiares em termos de ocupação territorial e descontinuidade, na medida em que a política habitacional, historicamente, promoveu o surgimento de conjuntos habitacionais espaçados em periferias distantes. O cenário conformou a rede urbana sem uma clara articulação entrepartes, a resultar no padrão de "colcha de retalhos".
A expressão contempla a ideia de um tecido urbano composto por conjuntos de fragmentos fragilmente articulados, o que reforça o caráter labiríntico. 0 resultado afeta os deslocamentos cotidianos, independente da origem ou estrato social. Por outro lado, as áreas urbanas menos privilegiadas tendem a coincidir com aquelas mais socialmente segregadas, reforçando um círculo negativo de apropriação e exclusão da e na cidade.

Autores como Villaça (1998) e Abramo (2007) evidenciaram também, a partir de outras abordagens, a estreita relação entre a questão habitacional e a segregação espacial. As feições são verificadas no processo de urbanização brasileiro em que a periferização e a exclusão socioespacial se deram, em grande medida, enquanto decorrência de uma política habitacional (ou da intencional ausência dela).

Diante desse contexto, o artigo explora as consequências das rápidas transformações ocorridas ao longo dos últimos anos nas cidades brasileiras a partir do Programa Minha Casa Minha Vida (PMCMV). 0 fenômeno contemporâneo de construção das cidades teve como contexto o ciclo de crescimento econômico nacional, que estimulou a atividade de construção civil para o enfrentamento da crise econômica. O programa foi lançado em 2009 pelo Governo Federal e, além de contribuir 
enquanto política anticíclica, objetivou reduzir o déficit habitacional ${ }^{1}$ e ampliar o mercado habitacional para o atendimento a famílias com até 10 salários mínimos (SM).

A partir da hipótese de que as características comprometidas de urbanização continuam a se reproduzir nas cidades do Brasil, a despeito da literatura abundante e conhecimento técnico sobre o tema, analisa-se de que maneira o PMCMV se relaciona com a estrutura urbana, em termos de segregação e integração espacial (acessibilidade entre partes), a partir das variáveis advindas da Teoria da Lógica Social do Espaço. Ou seja, busca-se investigar as relações entre território e a política habitacional, por meio da configuração da cidade (Figura 1).

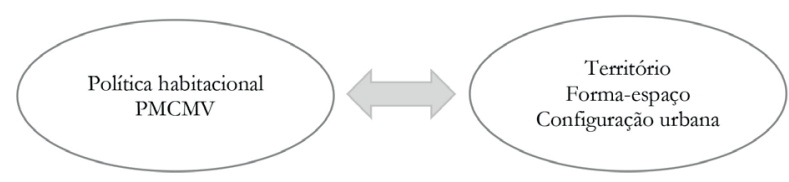

Figura 1 - Compreensão da relação entre as políticas públicas e o território. Fonte: Elaboração própria.

Delimitam-se como foco do estudo os empreendimentos contratados pelo PMCMV por meio do Fundo de Arrendamento Residencial - FAR, em 24 capitais brasileiras - Rio Branco/AC, Maceió/AL, Manaus/AM, Macapá/AP, Salvador/BA, Fortaleza/ CE, Brasília/DF, Goiânia/GO, São Luís/MA, Belo Horizonte/MG, Campo Grande/MS, Cuiabá/MT, Belém/PA, João Pessoa/PB, Recife/PE, Teresina/PI, Curitiba/PR, Natal/RN, Porto Velho/RO, Boa Vista/ RR, Porto Alegre/RS, Florianópolis/SC, Aracajú/SE e Palmas/TO - permitindo, a partir da análise comparativa, investigar características comuns e especificidades nos contextos urbanos analisados.

Ressalta-se ainda que o artigo se insere em um contexto de pesquisa mais amplo que abordou, além das variáveis configuracionais, medidas não oriundas da Sintaxe Espacial, bem como correlações entre os grupos de variáveis (cf. Carvalho, 2015).

1 Estima-se que o déficit habitacional brasileiro, em 2008, era de 5,5 milhões de moradias, sendo $83,5 \%$ localizados em áreas urbanas e $90 \%$ dele concentrado nas famílias com renda mensal de até 3 salários mínimos (SM) (Brasil, 2011).

\section{A Sintaxe espacial}

A Teoria da Lógica Social do Espaço ou Sintaxe Espacial apoia-se no conceito de configuração entendida como o arranjo das estruturas interdependentes de um determinado sistema, ou ainda, a maneira pela qual o objeto e suas partes relacionam-se entre si. Trata-se de um complexo de relações de interdependência com duas propriedades fundamentais: a configuração é diferente quando é vista de diferentes pontos, dentro de um mesmo sistema, e quando é vista apenas de uma parte do sistema (Hillier e Hanson, 1997, apud Medeiros, 2013). De acordo com Pereira et al. (2011, p. 7) "a configuração urbana de uma cidade seria constituída pelo seu sistema viário entendido sob uma perspectiva topológica, isto é, a partir das conexões entre suas vias tendo em vista uma interpretação relacional ou sistêmica".

Ler a cidade por sua configuração significa reconhecer nos seus vazios (ou permeabilidades) o espaço por onde circulam pedestres e veículos, ou seja, por onde se distribui o fluxo ou movimento que deve ser compreendido enquanto emblema da dinâmica urbana. Considerando, complementarmente, que malhas urbanas são produtos culturais, uma vez que sintetizam as transformações socioculturais ocorridas ao longo do tempo, é importante também compreendê-las como atuantes sobre os fluxos e o comportamento dos usuários, ao criarem campos de interação entre diferentes categorias de indivíduos. Significa que o espaço é produto de intenções sociais, mas também afeta a sociedade.

Entende-se, portanto, que a arquitetura (ou a forma-espaço) é, concomitantemente, variável dependente e variável independente (Holanda, 2002). Compreender a arquitetura enquanto variável dependente significa olhar o espaço como resultado do ambiente socionatural (geografia, relevo, interesses políticos e econômicos). Na condição de variável independente, por outro lado, compreende a percepção de que a arquitetura tem efeitos, afetando o ambiente e as pessoas de várias maneiras. De acordo com essa concepção, há uma relação fundamental entre espaço e sociedade, de maneira que não é possível haver uma sociedade sem conteúdo espacial, tampouco, um espaço sem conteúdo social.

Em termos metodológicos, os aspectos propostos pela Sintaxe Espacial possibilitam que fatores 
relacionados à configuração sejam quantificados e visualizados e, portanto, possam ser correlacionados com a infinidade de informações que envolvem estudos de natureza urbana (Medeiros, 2013). Utiliza-se nesta pesquisa a representação linear ou axial, técnica adotada em estudos urbanos para a identificação de diferentes probabilidades de circulação de pessoas. Sistemas urbanos demandam uma modelagem que parece ter na linha a simplificação necessária para a respectiva decodificação.

A leitura dos mapas axiais, em geral, ocorre segundo a interpretação da escala cromática ${ }^{2}$ aplicada aos números obtidos a partir dos cálculos da interação entre as linhas (ou vias) de determinado sistema: quanto mais quente for a cor, ou seja, tendendo para o vermelho, maior o valor de determinada variável. No extremo oposto, quanto mais fria a cor, próxima ao azul, menor o valor obtido. Em termos de integração, significa dizer que eixos mais integrados (mais vermelhos) são mais acessíveis e tendem a gerar mais fluxo potencial. Na medida em que são mais facilmente alcançados a partir de qualquer outro elemento do sistema (para o caso de uma interpretação global), são topologicamente mais curtos e por isso chamado de "rasos". Os eixos com menor valor de integração são menos permeáveis e denominados segregados ou profundos.

Os mapas axiais fornecem uma série de variáveis úteis para leitura da configuração urbana, denominadas de "configuracionais". As medidas permitem investigar propriedades específicas de determinada linha diante do sistema todo, a nível global, ou de partes, a nível local, consoante a interpretação de suas relações. Para a análise que se propõe são exploradas as seguintes medidas: a) conectividade (grau de conectividade ou número de cruzamento médio de vias em um sistema urbano, ou de uma via interpretada isoladamente); b) integração global (grau de acessibilidade entrepartes, com análise de todo o sistema urbano simultaneamente); c) integração local (grau de acessibilidade entrepartes, com abrangência analítica restrita ou local); d) escolha global (grau de escolha de caminhos em um sistema urbano, a expressar as rotas mais utilizadas para todos os trajetos possíveis de serem percorridos na cidade); e) controle (grau de controle de uma via em

2 Utiliza-se a escala cromática nesse estudo. Também é usual a adoção de tons de cinza e preto ou de variações na espessura da linha para indicação da escala. relação às demais, que lhe são contíguas); e f) controlabilidade (grau de dependência de uma via em relação às demais, que lhe são contíguas).

\section{Procedimentos}

A representação linear da malha viária compreende a modelagem da cidade. Para a pesquisa, considerou-se que o sistema urbano muitas vezes não coincide com o limite municipal, tendo em conta processos de avanço territorial e/ou conturbação/metropolização. À vista disso, os mapas axiais produzidos para as análises consideram o assentamento além dos seus limites administrativos, incluindo municípios próximos a depender do grau de conurbação (de unificação da malha urbana), e da dinâmica de amarração entre partes da estrutura urbana. Foram analisadas 24 capitais e seu entorno definidos a partir da mancha urbana contínua, estendendo a amostra para um total de 59 municípios analisados.

Em relação aos empreendimentos, foram utilizadas as imagens de satélites e ferramentas de geoprocessamento disponíveis no software Google Earth. A ação permitiu identificar a localização dos empreendimentos, que foram agrupados consoante o grau de contiguidade. A partir do mapeamento, identificou-se a via de acesso do empreendimento no mapa axial, para a extração de medidas configuracionais específicas processadas por meio do software Depthmap ${ }^{\circledR}$ (a Figura 2 e a Tabela 1 contém o exemplo do mapa axial de Goiânia e entorno e a identificação dos empreendimentos analisados para este sistema urbano).

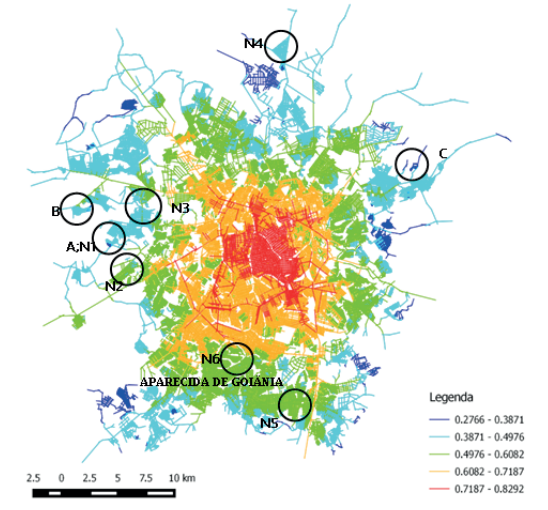

Figura 2 - Mapa axial de Goiânia e entorno e identificação dos empreendimentos.

Fonte: Elaboração própria. 
Tabela 1 - Integração Global dos contratos/empreendimentos em Goiânia/G0

\begin{tabular}{|c|c|c|c|c|}
\hline ID EMPREEND. & MUNICÍPIO & EMPREENDIMENTOS & Qtde UH & INT. Rn Base 100 \\
\hline Go-A & Goiânia & Conj Res. Bertim Belchior I & 200 & 37,3 \\
\hline Go-A & Goiânia & Conj Res. Bertim Belchior II & 353 & 37,3 \\
\hline Go-N1 & Goiânia & Portal Dos Ipes I, || E || & 272 & 36,5 \\
\hline Go-B & Goiânia & Jardim Do Cerrado - Mod III & 440 & 44,1 \\
\hline Go-B & Goiânia & Jardim Do Cerrado - Mod II & 448 & 44,1 \\
\hline Go-B & Goiânia & Jardim Do Cerrado - Mod I & 456 & 44,1 \\
\hline Go-B & Goiânia & Jardim Do Cerrado - Mod IV & 464 & 44,1 \\
\hline Go-B & Goiânia & Jardim Do Cerrado Fase 6 & 1.080 & 44,1 \\
\hline Go-N2 & Goiânia & Buena Vista I E III & 1.424 & 45,2 \\
\hline Go-N3 & Goiânia & Conj. Vera Cruz & 1.616 & 39,5 \\
\hline Go-N4 & Goiânia & Res. Antonio Carlos Pires & 214 & 29,3 \\
\hline Go-C & Goiânia & Res. Irisville II & 191 & 26,5 \\
\hline Go-C & Goiânia & Res. Irisville I & 200 & 26,5 \\
\hline Go-N5 & Ap. Goiânia & Res. Águas Claras & 336 & 52,3 \\
\hline Go-N6 & Ap. Goiânia & Res. Buriti Sereno & 832 & 59,6 \\
\hline \multirow[t]{5}{*}{9} & 2 & Med. Am. Contratos & 8.526 & 40,7 \\
\hline & & Med. Am. Empreendimentos & 8.526 & 41,1 \\
\hline & & Vmédio - Sistema & & 52,1 \\
\hline & & Vmáximo - Sistema & & 100,0 \\
\hline & & Vmínimo - Sistema & & 0,0 \\
\hline
\end{tabular}

Fonte: Elaboração própria.

\section{Sobre o programa Minha casa, Minha vida}

O Programa Minha Casa Minha Vida (PMCMV) foi lançado em 2009 pelo Governo Federal, com a intenção de estimular a atividade de construção civil para o enfrentamento da crise econômica ${ }^{3}$. Além disso, o programa tinha o objetivo de reduzir o déficit habitacional brasileiro e ampliar o mercado habitacional para o atendimento a famílias com renda média mensal de até $\mathrm{R} \$ 5 \mathrm{mil}^{4}$.

0 programa possui abrangência nacional e pode ser dividido em fases. Em sua primeira fase (PMCMV 1) foram contratadas 1 milhão de unidades habitacionais até 2010. Para a segunda fase do programa (PMCMV 2), estabeleceu-se a meta de outras 2,75 milhões de moradias entre 2011 e 2014. Os números demonstram a abrangência do programa presente em mais de $94 \%$ dos municípios brasileiros: até janeiro de 2015, eram 3,8 milhões de moradias

3 Crise internacional que teve origem nos Estados Unidos em 2008, a partir do colapso no sistema financeiro de títulos hipotecários de alto risco, conhecido como subprime.

4 Anteriormente utilizava-se o patamar de 10 salários mínimos. Em abril de 2016, o programa sofreu ajustes, ampliando a renda mensal para até $\mathrm{R} \$ 6.500,00$. Estas modificações recentes que contemplam a terceira fase do programa, entretanto, não serão abordadas no presente artigo. contratadas nas duas fases, e 2,1 milhões unidades habitacionais entregues ${ }^{5}$.

O PMCMV foi estruturado em três faixas de renda para atendimento das famílias, sofrendo alguns ajustes ao longo do tempo. Em sua segunda fase foram considerados os seguintes parâmetros: (a) Faixa 1: famílias com renda mensal até $\mathrm{R} \$ 1.600,00$; (b) Faixa 2: famílias com renda mensal até $\mathrm{R} \$ 3.275,00$; (c) Faixa 3: famílias com renda mensal até $\mathrm{R} \$ 5.000,00$. 0 programa divide-se ainda em dois subprogramas: (a) Programa Nacional de Habitação Urbana PNHU, destinado à produção ou aquisição de novas unidades habitacionais, ou requalificação de imóveis urbanos; e (b) Programa Nacional de Habitação Rural — PNHR, destinado à produção ou reforma de imóveis para agricultores familiares e trabalhadores rurais. Dentro do PNHU, estão as modalidades que se destinam ao atendimento das famílias enquadradas na faixa 1: (a) Fundo de Arrendamento Residencial (FAR) e (b) Fundo de Desenvolvimento Social (FDS) - Entidades, ambas atuam nos municípios acima de 50 mil habitantes; (c) Oferta Pública de Recursos - para municípios abaixo de

\footnotetext{
5 Caixa Econômica Federal. Data base: 30/01/15.
} 
50 mil habitantes ${ }^{6} .0$ atendimento às famílias enquadradas nas Faixas 2 e 3, por sua vez, dá-se a partir do financiamento habitacional que pode ocorrer de duas formas: (a) operação de balcão ou destinado à Pessoa Física que adquire um imóvel na planta; e (b) financiamento à produção ou destinado à Pessoa Jurídica (construtoras e incorporadoras).

A pesquisa concentra-se na modalidade FAR, considerada a principal do programa e que conta com a maior parcela de subsídios ao atender famílias com renda mensal de até $\mathrm{R} \$ 1.600$. Esta modalidade baseia-se na iniciativa privada, já que cabe a ela acessar diretamente os recursos do Fundo de Arrendamento Residencial - FAR, por meio da apresentação de projetos a serem avaliados e aprovados pelas instituições financeiras. Assim, alguns autores reforçam a crítica de que a produção da cidade - enquanto espaço urbano - está nas mãos do mercado privado ${ }^{7}$, interessado em garantir lucro e transformar a casa em mercadoria, produzindo grandes empreendimentos em áreas periféricas ${ }^{8}$.

Corroborando com as críticas desenvolvidas por Bonduki (2009), Fix \& Arantes (2009), além de Rolnik \& Nakano (2009), de que a estratégia adotada pelo PMCMV tende a contribuir com a periferização das intervenções, na medida em que não enfrenta a questão fundiária, pesquisas recentes têm evidenciado esse processo de periferização dos empreendimentos do PMCMV, reforçando as inquietações sobre as consequências do programa para o espaço urbano já tão marcado pela segregação socioespacial.

É o caso do estudo de Cardoso e Aragão (2013) que ao distribuir os empreendimentos do MCMV a partir de sua localização, em município núcleo e municípios periféricos das metrópoles, identificou uma tendência à periferização, principalmente nas metrópoles das regiões Nordeste e Sudeste. Este estudo evidencia ainda os casos das regiões metropolitanas de Belo Horizonte, Rio de Janeiro, Fortaleza

\footnotetext{
6 Mais detalhes sobre o funcionamento do programa podem ser vistos em Ferreira (2012) e Carvalho (2015).

7 Cardoso et al. (2011) demonstram como as empresas captam os lucros imobiliários e da construção.

8 Na medida em que a ampliação da escala dos empreendimentos tem como consequência a necessidade de trabalhar com terrenos de grandes dimensões, na maioria das vezes, disponível somente em áreas periféricas (Cardoso et al., 2011).
}

e Goiânia e as suas peculiaridades em relação a segregação espacial.

Aprofundando a análise da localização dos empreendimentos, dessa vez considerando o espaço intrametropolitano, menciona-se o estudo de Lima Neto et al. (2015) que investiga a produção habitacional do MCMV-FAR em confronto com o déficit habitacional, a partir da lógica locacional, em cinco Regiões Metropolitanas: RMs de Belém, Fortaleza, Belo Horizonte, Porto Alegre e Goiânia. O estudo apontou que na RM de Porto Alegre há uma estreita correlação entre a localização do déficit e da produção MCMV, estando no extremo oposto, os casos da RM de Belém e Goiânia. Para as RMs de Fortaleza e Belo Horizonte se verificou um grau médio de correspondência.

Além disso, ressalta-se que não é somente pela localização em si que se evidencia a segregação socioespacial, mas também pelos aspectos relacionados mais amplamente ao conceito de moradia adequada $^{9}$. 0 problema acontece em especial quanto à inserção urbana do empreendimento, em termos de serviços e equipamentos públicos urbanos, empregos, atividades, integração com a malha viária.

Assim, as críticas ao programa, exploradas no campo da política urbana, apresentam aspectos claramente visíveis no território das cidades e que parecem acentuar o quadro de fragmentação do tecido urbano. Portanto, surge, enquanto inquietação, a seguinte questão de pesquisa: É possível afirmar que o PMCMV tem contribuído para acentuar o quadro de fragmentação/dispersão do contexto urbano das cidades brasileiras?

\section{A análise do PMCMV na perspectiva configuracional}

A partir da sistematização das informações de cada sistema integrante da amostra, desenvolveu-se a base contendo todos os empreendimentos mapeados, permitindo investigar comparativamente os dados conforme características comuns e específicas.

\footnotetext{
9 "A moradia deve ser entendida de forma ampla, levando-se em conta, por exemplo, aspectos culturais do local onde se encontra e da comunidade que habita. Em muitos casos, o conceito de moradia adequada engloba o território, o acesso aos rios ou ao mar" (ONU, 2010).
} 
As variáveis configuracionais foram então abordadas a partir de duas perspectivas: global e local. A perspectiva global auxilia na compreensão das relações entre o empreendimento e a cidade como um todo, em oposição à perspectiva local, que avalia o papel da via de acesso ao empreendimento ante seu entorno imediato. Para a análise global foram utilizadas as variáveis Integração Rn (ou global) - Base 100 (Medeiros, 2013) e Escolha Rn (ou global). Para a local, foram exploradas: Conectividade, Integração R3, Controle e Controlabilidade.

\section{Integração global - Base 100}

A medida de integração global expressa o potencial da acessibilidade topológica de cada uma das vias de acesso ao empreendimento em relação ao complexo urbano como um todo. A média corresponde ao valor médio de todos os empreendimentos de determinado sistema, desta vez considerando as medidas normalizadas para base 100 . Com a comparação produzida em um mesmo intervalo (que varia de 0 a 100, denominada de base 100) é possível perceber mais claramente o desempenho dos empreendimentos em relação à amostra.

A análise permitiu evidenciar uma expressiva variação entre 32,5 (Palmas/TO) e 66,1 (João Pessoa/PB). Significa que os empreendimentos de Palmas são relativamente menos integrados (mais segregados), em média, do que aqueles de João Pessoa (menos segregados).

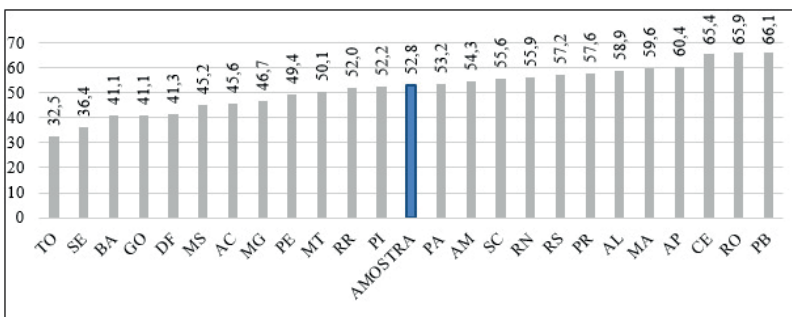

Figura 3 - Integraç̃ão Rn - Base 100, média dos empreendimentos. Fonte: Elaboração própria.

Ao confrontar a média da amostra com a média dos valores das cidades, é possível refinar a interpretação. Se a média dos empreendimentos for próxima à média de toda a cidade, significa que o sistema é efetivamente segregado (a segregação é relativizada, pois todo o sistema apresenta desempenho comprometido). Quando a distância for significativa, os empreendimentos: a) são segregados em um cenário geral de melhor articulação (a segregação é acentuada, pois o sistema, grosso modo, é bem articulado), ou b) são integrados, pois a média dos empreendimentos é superior à média do sistema. Os resultados permitem, portanto, perceber o quanto os empreendimentos se distanciam ou aproximam dos polos, de modo a explorar com mais sincronia o cenário de determinado contexto urbano por meio de uma leitura global comparada, como expresso na Figura 4.

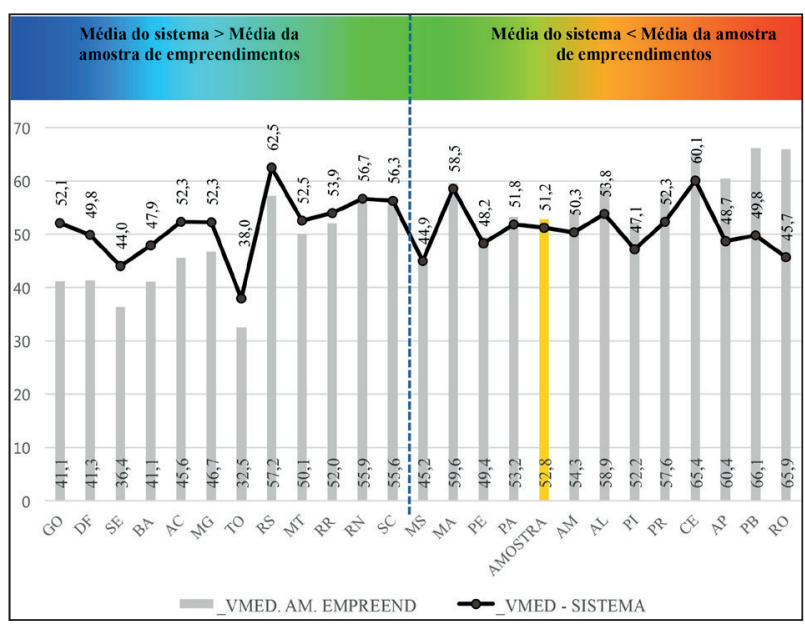

Figura 4 - Integração Rn base 100 - média dos empreendimentos e média do sistema. Fonte: Elaboração própria.

No respectivo gráfico, os dados estão ordenados considerando a diferença entre a média de integração dos empreendimentos e a média de integração de cada sistema. Quanto mais à esquerda ou quanto mais azul, maior a distância entre esses valores, evidenciando casos em que os empreendimentos tendem para a segregação do tecido na medida em que possuem valores menores do que a média do sistema. No extremo oposto, ou seja, quanto mais vermelho, estão os casos em que a média de integração da amostra de empreendimentos é maior que a média do sistema, apontando os casos em que a inserção urbana do empreendimento é mais positiva ou mais central.

Dos 24 sistemas analisados, em 12 deles os empreendimentos são melhor integrados que a média do sistema, enquanto nos outros 12 ocorre o contrário. As situações mais segregadas incluem Goiânia/ 
GO, Brasília/DF, Aracaju/SE, Salvador/BA, Rio Branco/AC, Belo Horizonte/MG, Palmas/TO, Porto Alegre/RS, Cuiabá/MT, Boa Vista/RR, Natal/RN e Florianópolis/SC, destacando-se Goiânia/GO para a situação mais extrema. Os contextos de maior integração global incorporam Campo Grande/MS, São Luís/MA, Recife/PE, Belém/PA, Manaus/AM, Maceió/AL, Teresina/PI, Curitiba/PR, Fortaleza/CE, Macapá/AP, João Pessoa/PB e Porto Velho/RO, destacando-se o último com maior diferença entre os valores médios do sistema e do empreendimento.

\section{Escolha Global - Rn}

A variável Escolha Rn, conforme aplicado à presente pesquisa, permite constatar o potencial de fluxo da via de acesso dos empreendimentos (a chance de vir a ser escolhida em todos os trajetos passíveis de serem realizados na rede urbana) em relação a todas as outras do sistema, o que remete para uma análise da hierarquia viária. A medida não deve ser adotada, entretanto, para uma comparação direta entre sistemas, pois o valor numérico é produto da quantidade de eixos que integram a representação linear (há significativa variação).

Na Figura 5 estão dispostos de valores de escolha médios, máximos e mínimos de cada cidade da amostra. A leitura procedida procura evidenciar a acessibilidade aos conjuntos, uma vez que vias com alto potencial de escolha tendem a estar associadas a eixos bem servidas em termos de transporte coletivo e infraestrutura.

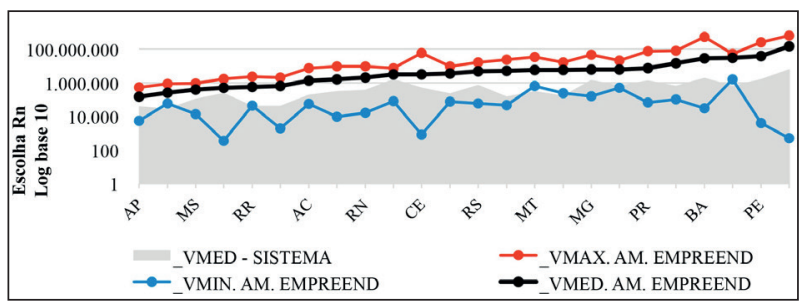

Figura 5 - Escolha Global Rn, valor máximo, médio e mínimo dos empreendimentos e média do sistema.

Fonte: Elaboração própria.

Os resultados apontam que os contextos de São Luís/MA, Salvador/BA, Manaus/AM, Recife/PE e Brasília/DF possuem médias elevadas e significativamente acima da amostra, revelando que os empreendimentos, em geral, situam-se em vias relevantes para os deslocamentos no sistema urbano. Em Aracajú/SE e Florianópolis/SC, a média está próxima ao sistema, o que aponta para uma melhor articulação diante da cidade.

Pode-se considerar também que uma menor amplitude em relação aos valores máximo e mínimo indica sistemas mais homogêneos, o que tende a minimizar diferenças, suavizando a segregação — é o que ocorre em Porto Velho/RO, Cuiabá/MT e Goiânia/GO. No extremo oposto, verificam-se os casos de Brasília/ DF e Fortaleza/CE, em que há uma grande amplitude entre os valores máximos e mínimos.

Percebem-se ainda casos que mesmo os empreendimentos com menores valores de escolha (valor mínimo da amostra de empreendimentos) estão em vias com potencial de fluxo acima da média do sistema, a exemplo de Porto Velho/RO, Boa Vista/RR, Cuiabá/MT e Maceió/AL.

Considera-se importante ponderar que, se por um lado a proximidade dos empreendimentos a vias com elevado potencial de fluxo tende a revelar facilidade no acesso a transporte coletivo, por outro lado, há que se levar em conta as características locais do canal de comunicação. Ou seja, um empreendimento nas proximidades de uma rodovia (por exemplo) pode revelar facilidades de acesso a transporte coletivo, mas fragilidades de conexão com o tecido urbano em nível local, conforme explorado na seção a seguir.

\section{Integração Local - R3}

Diferentemente do que ocorre na escala global, onde se evidenciam aspectos relacionados à segregação, em termos de integração local (Figura 6), a média dos empreendimentos é maior que a média do sistema. É possível concluir que, que no âmbito do bairro ou de seu entorno imediato, as moradias associadas ao PMCMV dispõem-se em espaços mais acessíveis.

Os dados do gráfico estão ordenados de forma crescente em relação a essa diferença, ou seja, em Aracajú/SE, os empreendimentos estão em vias pouco mais integradas em relação à média, diferentemente do que em Brasília/DF, onde os empreendimentos estão em vias muito mais integradas, em termos locais, do que a média do sistema. 


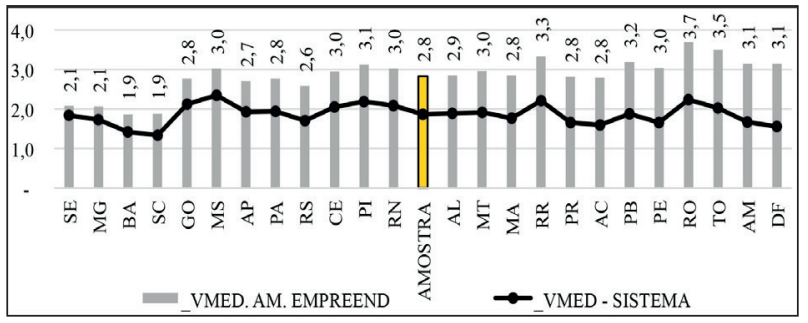

Figura 6 - Integração R3 - média dos empreendimentos e média dos sistemas.

Fonte: Elaboraç̃ão própria.

\section{Conectividade}

Em relação à variável, que expressa a quantidade de conexões de cada eixo, verifica-se que em todos os sistemas analisados a média da conectividade das vias de acesso é maior que a média do sistema. 0 resultado (Figura 7) aponta que, em maior ou menor grau, os empreendimentos se situam em vias bem alimentadas ou costuradas, o que dialoga com os achados de integração global, local e de escolha.

Os dados apresentados no gráfico estão ordenados considerando a diferença entre esses valores, ou seja, no caso de Florianópolis/SC a diferença entre a média de empreendimentos e a média do sistema é mínima, diferentemente do caso de Porto Velho/RO, em que alcança um valor significativo. São dados de características locais e sabe-se que há uma vigorosa associação entre a forma de articulação das malhas viárias e os potenciais de acessibilidade encontrados para cada eixo em um mapa axial (Medeiros, 2013).

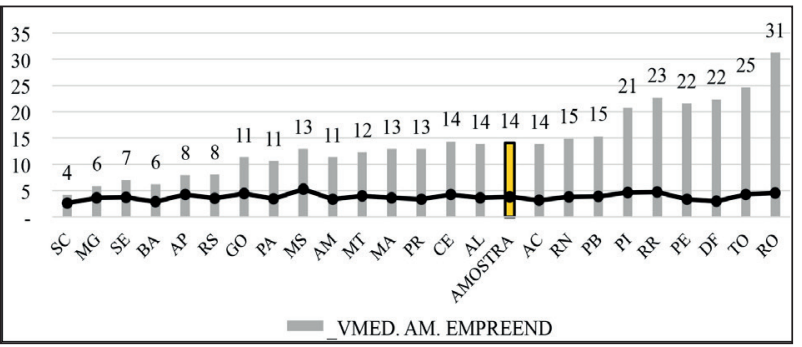

Figura 7 - Conectividade - média dos empreendimentos e média dos sistemas.

Fonte: Elaboração própria.

\section{Controle}

A variável controle exprime o grau de dominância da via em relação ao entorno imediato, ou seja, para uma via apresentar alto controle precisa ser muito conectada, mas os eixos conectados devem ter baixa conectividade. Trata-se de uma variável de natureza local que revela um padrão de "ilhas" de acesso (há um acesso único ao empreendimento - Figura 8).

Em termos médios, os dados apontam que, para todos os sistemas analisados (Figura 8), as médias dos empreendimentos são maiores que as médias dos sistemas. Vale o registro, por exemplo, dos casos de Porto Velho/ RO, Recife/PE, Brasília/DF, em que as vias de acesso aos empreendimentos compreendem eixos dominantes associados em um padrão de "ilhas" de acesso, em contraponto a sistemas como Macapá/AP, Florianópolis/SC, Belo Horizonte/MG, que não o seguem.

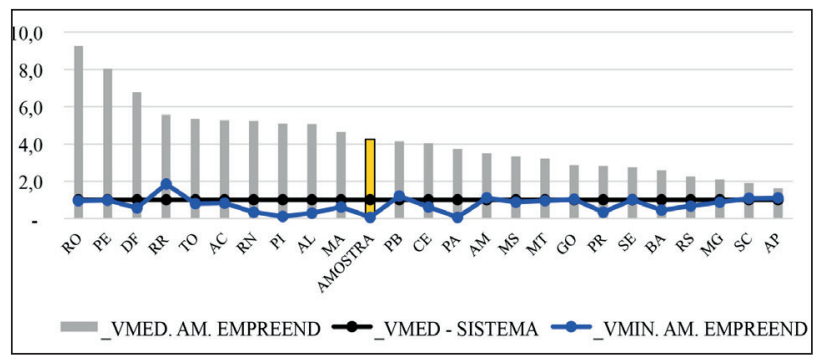

Figura 8 - Controle, comparativo média dos empreendimentos e média dos sistemas.

Fonte: Elaboraç̃ão própria.

Ilustra-se como exemplo do padrão o Res. Cidade do Povo em Rio Branco/AC (que possui o valor máximo de controle em relação à amostra de empreendimentos), situado ao longo de uma rodovia (BR 364) (Figura 9).

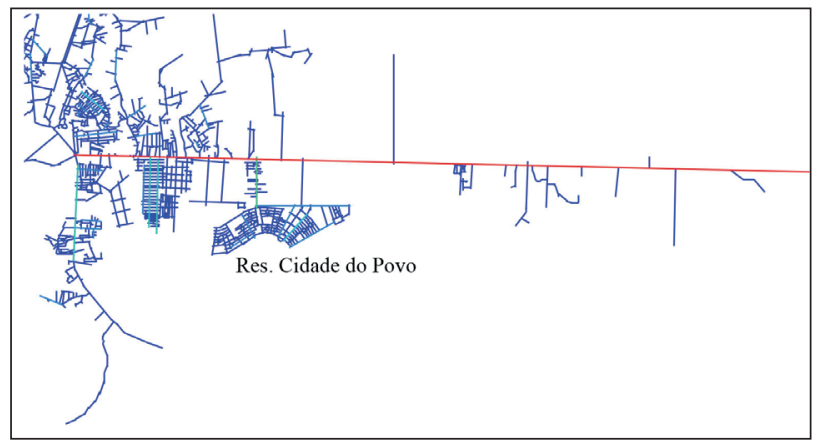

Figura 9 - Trecho do mapa de controle de Rio Branco/AC. Fonte: Elaboraccão própria. 


\section{Contrabilidade}

Diferentemente da variável de controle, em que a média dos empreendimentos é significativamente superior à média do sistema em quase todos os casos, os dados de controlabilidade expressaram, que, de maneira geral, as médias dos empreendimentos estão próximas às do sistema.

Ressalta-se que quanto menor esse valor, menor a dependência em relação a outras vias, o que tende a ser mais desejável do ponto de vista das possibilidades de acesso e da costura entre as partes. Citamse os casos de Macapá/AP e Manaus/AM como locais onde os empreendimentos do PMCMV estão em vias menos "dominadas", em termos topológicos, do que a média do sistema (Figura 10).

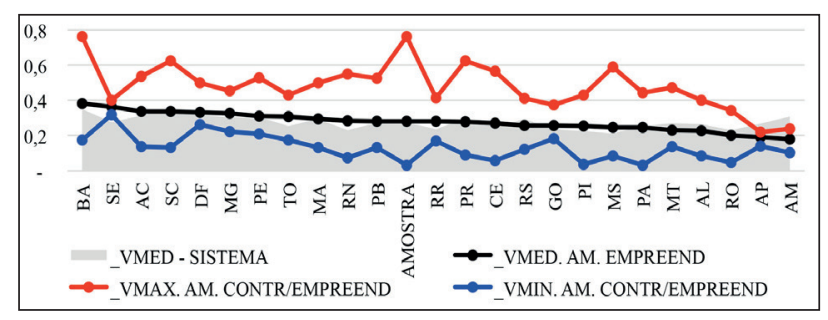

Figura 10 - Controlabilidade - Valores médio, máximo e mínimo dos empreendimentos e média dos sistemas.

Fonte: Elaboração própria.

Por outro lado, ilustra-se o caso Salvador/BA, com uma elevada média dos valores de controlabilidade: a cidade apresenta o empreendimento com o maior grau de dependência da amostra.

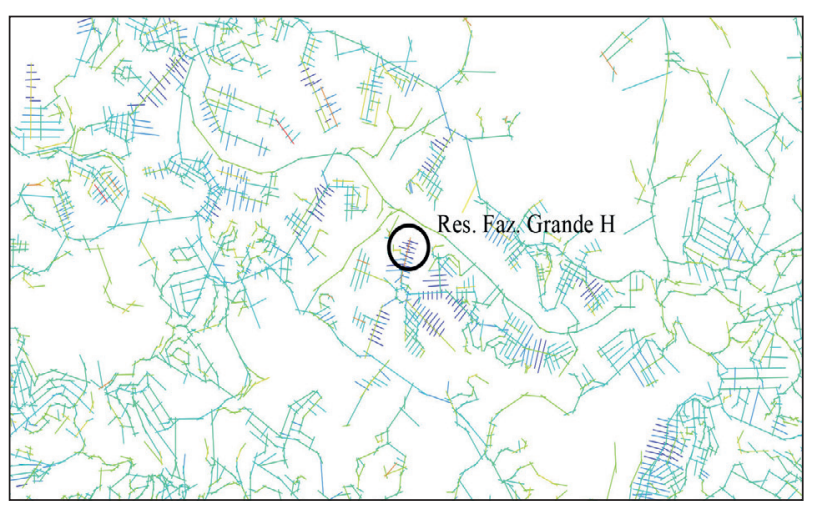

Figura 11 - Controlabilidade, trecho do mapa de Salvador/BA. Fonte: Elaboração própria.

\section{Conclusões}

A pesquisa buscou analisar o processo contemporâneo de construção das cidades, considerando a relação entre o Programa Minha Casa Minha Vida e o espaço urbano. A partir da análise configuracional, conforme a Teoria da Lógica Social do Espaço ou Sintaxe Espacial, buscou-se explorar as relações entre as políticas públicas e o território, segundo a investigação da inserção urbana dos empreendimentos do PMCMV, na modalidade FAR.

A análise comparativa, a partir da média de integração na base 100, permitiu identificar que em doze dos casos analisados, os empreendimentos têm maior valor de integração que a média do sistema. Para estes casos, a inserção tende para a integração do tecido, o que requer a ressalva sobre a leitura do PMCMV ser exclusivamente de reforço da periferização.

Em termos locais, os dados apontaram que os empreendimentos se dispõem em espaços acessíveis, verificando que em todos os sistemas a média de integração do empreendimento é maior do que a do sistema. Ainda na perspectiva local, verificou-se a partir da medida de controle, que a média dos empreendimentos é significativamente superior à média do sistema em quase todos os casos, apontando que as vias de acesso são dominantes a considerar a recorrência do um padrão em "ilhas".

Os dados de controlabilidade identificaram, por sua vez e de maneira geral, que a média dos empreendimentos está próxima à média dos sistemas. 0 achado aponta que não se identifica um maior grau de dominância das vias de acesso aos empreendimentos do programa em relação às demais áreas das cidades.

As descobertas da pesquisa permitiram revelar que a associação direta entre o PMCMV e a fragmentação/periferização precisa ser relativizada. Há variações de desempenho na amostra, mas não é possível reputar ao programa, de maneira generalizada, o agravamento de um quadro de descontinuidade urbana que vem sendo uma característica das cidades do país há décadas. Vários resultados apontam para estratégias de consolidação do tecido que, grosso modo, servem para articular partes das cidades. 
Em relação ao aspecto configuracional, ao permitir que os dados sejam matematicamente quantificados e correlacionados, acredita-se que a metodologia e as ferramentas advindas da Sintaxe Espacial são úteis na leitura urbana e possibilitam aprofundar o debate acerca da inserção urbana dos empreendimentos, em termos potenciais. A opção contribui para o processo de sistematização das análises comparadas, de modo a identificar as relações entre as características dos empreendimentos e seus atributos configuracionais.

Considera-se, à guisa de conclusão, que o estudo explora o Programa Minha Casa, Minha Vida demonstrando de que maneira o programa, desenhado em nível federal, possui diferentes abordagens e resultados a depender das políticas e dinâmicas urbanas locais. Além disso, a análise contribui para uma reflexão acerca das dificuldades existentes no planejamento e na gestão urbana em cidades brasileiras, principalmente em contextos urbanos que extrapolam os limites geográficos, uma vez que os problemas habitacionais se impõem para além dos limites políticos e institucionais. Assim, ao identificar e tratar contextos urbanos consoante a formação da mancha urbana, discute-se a importância de um olhar metropolitano, na medida em que as relações entre o local de moradia, de emprego e de serviços se traduzem em realidades complexas. A formação de subcentralidades, as relações de mobilidade que possibilitam local de moradia e trabalho que avançam além dos limites municipais, a implantação de empreendimentos para atender famílias oriundas de outros municípios são exemplos da complexa realidade que se impõe enquanto um desafio para a análise urbana.

\section{Referências}

Abramo, P. (2007). A mão inoxidável do mercado e a produção da estrutura urbana nas grandes metrópoles latino-americanas. R. B. Estudos urbanos e regionais, 9(2) 2554. Recuperado em 04, julho e 2017, de http://inctpped. ie.ufrj.br/spiderweb/dymsk_5/5.3-1\%20Abramo.pdf

Brasil, Ministério das Cidades (2011). Déficit Habitacional no Brasil 2008. Brasília: Ministério das Cidades.
Bonduki, N. (2009, 01 de maio). Do Projeto Moradia ao Programa Minha Casa Minha Vida. TD. Teoria e Debate. Recuperado em 04 de julho de 2017, de http://www. teoriaedebate.org.br/materias/nacional/do-projeto-moradia-ao-programa-minha-casa-minha-vida.

Cardoso, A. L, Aragão, T. A. (2013). Do fim do BNH ao programa minha casa minha vida: In: Cardoso, A. L. $O$ Programa Minha Casa Minha Vida e seus efeitos territoriais (1aㅡ Edição, Volume 1). Rio de Janeiro: Letra Capital.

Cardoso, A. L., Aragão, T. A., Araujo, F. S. (2011). Habitação de interesse social: política ou mercado? Reflexos sobre a construção do espaço metropolitano. In XIV Encontro Nacional da Anpur (p. 01-20), Rio de Janeiro: ANPUR.

Carvalho, A. (2015). Da moradia à colcha de retalhos: o processo de construção de cidades à luz do Programa Minha Casa, Minha Vida (Dissertação de Mestrado).

Faculdade de Arquitetura e Urbanismo, Universidade de Brasília, Brasilia.

Ferreira, J. S. W. (2012). Produzir casas ou Construir Cidade? Desafios para um novo Brasil urbano (1를 Edição, Volume 1). São Paulo: LABHAB: FUPAM.

Fix, M, \& Arantes, P. F. (2009). Como o governo Lula pretende resolver o problema da habitação. Correio da Cidadania. Recuperado em 31 de outubro de 2013, de http://www.correiocidadania.com. $\mathrm{br} /$ index.php?option=com_content $\&$ view=category \&layout=blog\&id=66\&Itemid=171

Hillier, B, Hanson, J. (1997) The reasoning art: or, the need for an analytical theory of architecture. In: 1st International Space Syntax Symposium, 1997, Inglaterra. Proceedings. Londres: Space Syntax Laboratory / The Bartlett School Of Graduate Studies / University College London, p. 01.1-01.05.

Holanda, F. (2002). O espaço de exceção (1a Edição, Volume 1). Brasília: Editora Universidade de Brasília.

Lima Neto, V. C., Krause, C., \& Furtado, B. A. (2015). 0 déficit habitacional intrametropolitano e a localização de empreendimentos do Programa Minha Casa Minha Vida: mensurando possibilidades de atendimento. Texto para discussão, n. 2044. Brasília: IPEA.

Medeiros, V. (2013). Urbis brasiliae: o labirinto das cidades brasileiras (1a Edição, Volume 1). Brasília: Editora Universidade de Brasília. 
Organização das Nações Unidas - ONU. (2010). Relatora Especial da ONU para a Moradia Adequada. Como atuar em projetos que envolvem despejos e remoções?. Guia. São Paulo: ONU, 2010. Recuperado em 25 de janeiro de 2017, de http://direitoamoradia.org/

Pereira, R., Barros, A., Holanda, F., \& Medeiros, V. (2011). 0 uso da sintaxe espacial na análise do desempenho do transporte urbano: limites e potencialidades. Texto para Discussão, n. 1630. Rio de Janeiro: IPEA.

Rolnik, R., \& Nakano, K. (2009). As armadilhas do Pacote Habitacional. Le Monde Diplomatique Brasil (05 de março de 2009). Recuperado em 15 de setembro de 2016, de http://www.diplomatique.org.br/artigo.php?id=461
Villaça, F. (1998). Espaço intra-urbano no Brasil (2 $2^{\mathrm{a}}$ Edição, Volume 1), São Paulo: Lincoln Institute: Studio Nobel: FAPESP.
Recebido: Nov. 07, 2016

Aprovado: Fev. 01, 2017 